\title{
Self-cleaning semiconductor heterojunction substrate: ultrasensitive detection and photocatalytic degradation of organic pollutants for environmental remediation
}

\author{
Mingyue Hu${ }^{1,2,3}$, Yingnan Quan ${ }^{1,2,3}$, Shuo Yang ${ }^{4}$, Rui Su${ }^{5}$, Huilian Liu ${ }^{1,2,3}$, Ming Gao $\mathbb{B}^{1,2,3}$, Lei Chen ${ }^{1,2,3}$ and \\ Jinghai Yang ${ }^{1,2,3}$
}

\begin{abstract}
Emerging technologies in the field of environmental remediation are becoming increasingly significant owing to the increasing demand for eliminating significant amounts of pollution in water, soil, and air. We designed and synthesized $\mathrm{MoS}_{2} / \mathrm{Fe}_{2} \mathrm{O}_{3}$ heterojunction nanocomposites (NCs) as multifunctional materials that are easily separated and reused. The trace detection performance of the prepared sample was examined using bisphenol A (BPA) as the probe molecule, with limits of detection as low as $10^{-9} \mathrm{M}$; this detection limit is the lowest among all reported semiconductor substrates. BPA was subjected to rapid photocatalytic degradation by $\mathrm{MoS}_{2} / \mathrm{Fe}_{2} \mathrm{O}_{3} \mathrm{NCs}$ under ultraviolet irradiation. The highly recyclable $\mathrm{MoS}_{2} / \mathrm{Fe}_{2} \mathrm{O}_{3} \mathrm{NCs}$ exhibited photo-Fenton catalytic activity for BPA and good detection ability when reused as a surface-enhanced Raman scattering (SERS) substrate after catalysis. The SERS and photocatalysis mechanisms were proposed while considering the effects of the Z-scheme charge-transfer paths, three-dimensional flower-like structures, and dipole-dipole coupling. Moreover, the prepared $\mathrm{MoS}_{2} / \mathrm{Fe}_{2} \mathrm{O}_{3} \mathrm{NCs}$ were successfully applied in the detection of BPA in real lake water and milk samples. Herein, we present insights into the development of $\mathrm{MoS}_{2} / \mathrm{Fe}_{2} \mathrm{O}_{3}$ materials, which can be used as multifunctional materials in chemical sensors and in photocatalytic wastewater treatments for the removal of recalcitrant organic pollutants.
\end{abstract}

\section{Introduction}

Serious environmental pollution and accelerated global warming are attributed to the rapid consumption of fossil fuels, the increasing population, and the rapid development of the economy. Thus, the development of innovative and renewable environmental remediation materials is becoming increasingly important ${ }^{1-6}$. Since mechanically exfoliated graphene was discovered, the development of

\footnotetext{
Correspondence: Ming Gao (gaomingphy@126.com) or

Lei Chen (chenlei@jlnu.edu.cn) or Jinghai Yang (jhyang1@jlnu.edu.cn)

${ }^{1}$ Key Laboratory of Functional Materials Physics and Chemistry of the Ministry

of Education, Jilin Normal University, 130103 Changchun, People's Republic of China

${ }^{2}$ National Demonstration Centre for Experimental Physics Education, Jilin Normal University, 136000 Siping, People's Republic of China

Full list of author information is available at the end of the article
}

two-dimensional (2D) materials consisting of atomically thin crystal layers bound by van der Waals forces has accelerated owing to the potential applications of these materials in optoelectronics, catalysis, new technologies, and electricity ${ }^{7-9}$. 2D-MoS 2 nanosheets are excellent layered materials, having unique layered structures and large surface areas. It is important to investigate methods for improving the chemical properties of $\mathrm{MoS}_{2}$, which may affect its application in electronic devices, catalysis, and molecular sensing ${ }^{10}$. A popular method for improving the properties of $\mathrm{MoS}_{2}$ is the decoration of $\mathrm{MoS}_{2}$ with noble metal nanoparticles. For instance, a $\mathrm{MoS}_{2} /$ noble metal nanoparticle composite can induce local surface plasmon resonance (LSPR) for activating the photoelectrocatalysis of $\mathrm{H}_{2}$ and enhancing the light absorption or emission of 
$\mathrm{MoS}_{2}$. Moreover, the LSPR can generate surface-enhanced Raman scattering (SERS), which can be used in biological and chemical sensing applications ${ }^{11-13}$. Among various traditional noble metal materials, Au nanomaterials are the most widely used SERS substrate material ${ }^{14-16}$. However, the high cost and specialized instruments required for $\mathrm{Au}$ substrates hinder their practical application. Due to its very high SERS activity, Ag is another widely studied substrate material ${ }^{17}$. Although the price of Ag is much lower than the price of $\mathrm{Au}$, the main defect of $\mathrm{Ag}$ is its poor stability, which easily oxidizes in air. To address these problems, it is essential to exploit synergistic effects by incorporating inexpensive and stable semiconductors.

Thus far, a few $\mathrm{MoS}_{2}$-based heterostructures, such as $\mathrm{CdS} / \mathrm{MoS}_{2}, \mathrm{TiO}_{2} / \mathrm{MoS}_{2}$, and $\mathrm{MoO}_{3} / \mathrm{MoS}_{2}$, have exhibited higher photocatalytic efficiencies than pristine $\mathrm{MoS}_{2}{ }^{18-20}$. Investigations have been continuously conducted on the efficient separation of a nanocomposite (NC) from a treated effluent, along with the subsequent reusability of the NC. Several research groups have begun to focus on magnetically separable photocatalysts for wastewater treatment, demonstrating the value of the special properties of magnetic materials. Among these magnetic materials, $\mathrm{Fe}_{2} \mathrm{O}_{3}$ has a narrow bandgap, high chemical resistance, and high resistance to corrosion. Therefore, rationally designed $\mathrm{MoS}_{2} / \mathrm{Fe}_{2} \mathrm{O}_{3} \mathrm{NCs}$ can serve as a reusable SERS substrate for detection and easily reclaimed photocatalyst. The recovery and economical reuse of $\mathrm{MoS}_{2} / \mathrm{Fe}_{2} \mathrm{O}_{3} \mathrm{NCs}$ photocatalysts is easily achieved by adding an external magnetic field.

Bisphenol A (BPA) is believed to be an endocrine disruptor and widely exists in food containers and the environment. Even low levels of BPA entering the body can disrupt the endocrine system by binding to estrogen receptors, which may lead to cardiovascular diseases, immune function deficiencies, impaired reproductive capacity, and other diseases $^{21-23}$. Thus, it is imperative to develop a facile, rapid, and inexpensive method for BPA detection and degradation.
In this study, $\mathrm{MoS}_{2} / \mathrm{Fe}_{2} \mathrm{O}_{3} \mathrm{NCs}$ were prepared via a simple low-temperature hydrothermal method, and the advantages of the two materials were combined. For example, after $50 \mathrm{~min}$ of ultraviolet (UV) irradiation, the substrate completely degraded BPA, and upon recovery, demonstrated its detection capability. Compared with $\mathrm{MoS}_{2}$ NFs and $\mathrm{Fe}_{2} \mathrm{O}_{3}$ NPs, the rate of degradation of BPA and the SERS activity of $\mathrm{MoS}_{2} / \mathrm{Fe}_{2} \mathrm{O}_{3}$ NCs were significantly better. This new, easily recoverable SERS sensor with a high sensitivity will facilitate sensing harmful molecules. To the best of our knowledge, no $\mathrm{MoS}_{2} / \mathrm{Fe}_{2} \mathrm{O}_{3}$ composites that exhibit BPA detection and photocatalysis multifunctionality have been reported thus far. Photocatalytic and SERS mechanisms were also proposed.

\section{Results and discussion}

\section{Characterization analysis of $\mathrm{MoS}_{2} / \mathrm{Fe}_{2} \mathrm{O}_{3} \mathrm{NCs}$}

A growth flow diagram of the $\mathrm{MoS}_{2} / \mathrm{Fe}_{2} \mathrm{O}_{3} \mathrm{NCs}$ is shown in Fig. 1. Figure 2a confirms that the $\mathrm{MoS}_{2}$ sample was pure hexagonal $2 \mathrm{H}-\mathrm{MoS}_{2}$ (JCPDS card no. 37-1492). The peak with the highest intensity (at $2 \theta=14.09^{\circ}$ ) indicated that $\mathrm{MoS}_{2}$ had excellent lamellar growth in the $c$-axis direction. In regard to $\mathrm{MoS}_{2} / \mathrm{Fe}_{2} \mathrm{O}_{3}$, some of the peaks corresponded to $2 \mathrm{H}-\mathrm{MoS}_{2}$, while others corresponded to tetragonal $\gamma-\mathrm{Fe}_{2} \mathrm{O}_{3}$ (JCPDS card no. 39-1346) phase, indicating that the native structure of each constituent was well preserved during the reaction. The intensities of the $\mathrm{MoS}_{2}$ peaks for the $\mathrm{MoS}_{2} / \mathrm{Fe}_{2} \mathrm{O}_{3} \mathrm{NCs}$ were lower than those for pure $\mathrm{MoS}_{2}$ because the $\mathrm{Fe}_{2} \mathrm{O}_{3}$ NPs attached to the $\mathrm{MoS}_{2}$ nanoflowers (NFs). Raman spectra confirmed the chemical composition of the $\mathrm{MoS}_{2} / \mathrm{Fe}_{2} \mathrm{O}_{3} \mathrm{NCs}$ and $\mathrm{MoS}_{2}$. Two characteristic Raman peaks of $\mathrm{MoS}_{2}$ were observed at 337 and $377 \mathrm{~cm}^{-1}$, corresponding to the $A_{1 \mathrm{~g}}$ and ${ }^{1} E_{2 \mathrm{~g}}$ vibration modes, respectively; additionally, their peak frequency difference was $\Delta k=40 \mathrm{~cm}^{-1}$ (Fig. 2b) ${ }^{24-26}$. However, after the incorporation of $\mathrm{Fe}_{2} \mathrm{O}_{3}$, the characteristic Raman peaks of $\mathrm{MoS}_{2}$ shifted to 338 and $379 \mathrm{~cm}^{-1}$, and the peak frequency difference was $\Delta k=41 \mathrm{~cm}^{-1} . \Delta k$ represents the number of



Fig. 1 Preparation process and application of $\mathrm{MoS}_{2} / \mathrm{Fe}_{2} \mathrm{O}_{3} \mathrm{Cs}$. Schematic showing the preparation process and application of $\mathrm{MoS}_{2} / \mathrm{Fe} \mathrm{O}_{3} \mathrm{NCs}$. 
a

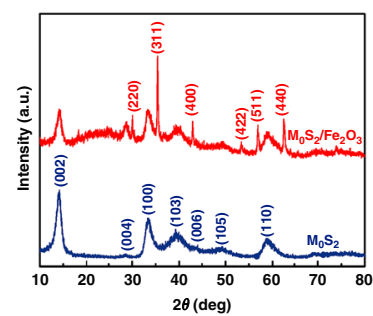

b





d

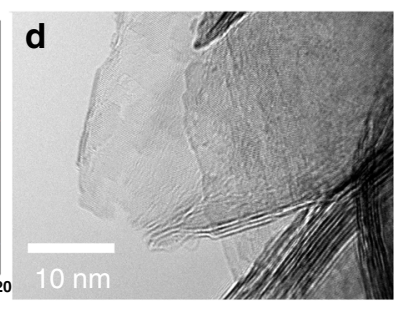

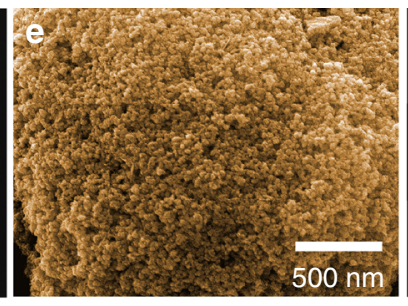
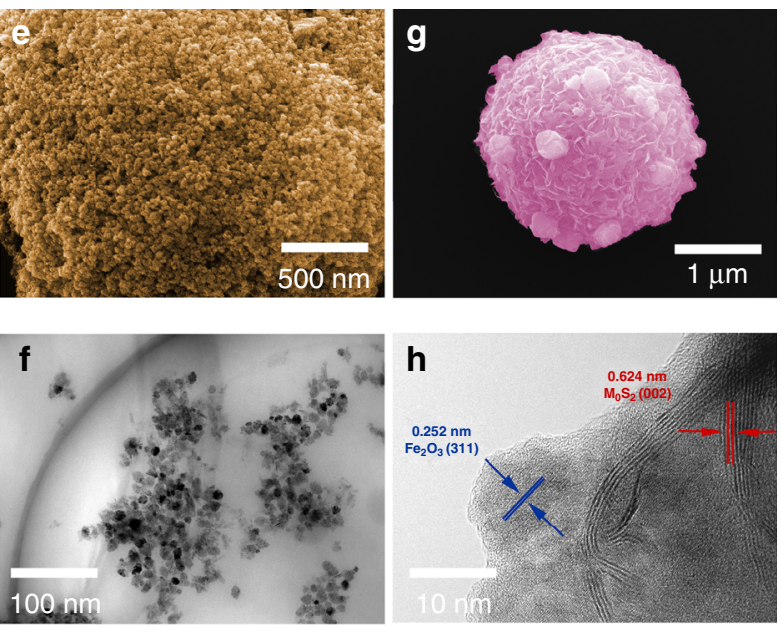


Fig. 2 Structural quality and morphology of $\mathrm{MoS}_{2} / \mathrm{Fe}_{2} \mathrm{O}_{3}$ NCs. a XRD patterns of $\mathrm{MoS}_{2}$ and $\mathrm{MoS}_{2} / \mathrm{Fe}_{2} \mathrm{O}_{3}$. $\mathbf{b}$ Raman spectra of $\mathrm{MoS}_{2}$ and $M o S_{2} /$ $\mathrm{Fe}_{2} \mathrm{O}_{3}$. c SEM images of $\mathrm{MoS}_{2}$ NFs. d TEM image of typical $\mathrm{MoS}_{2}$ NFs. e SEM image of $\mathrm{Fe}_{2} \mathrm{O}_{3}$ NPs. $\mathbf{f}$ TEM image of the Fe $\mathrm{O}_{3} \mathrm{NPS}$. $\mathbf{g} \mathrm{SEM}$ image of $\mathrm{MoS}_{2} / \mathrm{Fe}_{2} \mathrm{O}_{3} \mathrm{NCS}$. $\mathbf{h}$ HRTEM image of $\mathrm{MoS}_{2} / \mathrm{Fe}_{2} \mathrm{O}_{3} \mathrm{NCs}$. $\mathbf{i}-\mathbf{m}$ Typical STEM image of $\mathrm{MoS}_{2} / \mathrm{Fe}_{2} \mathrm{O}_{3}$ and the corresponding elemental mapping images of $\mathrm{Mo}, \mathrm{S}, \mathrm{Fe}$, and $\mathrm{O}$.

$\mathrm{MoS}_{2}$ layers ${ }^{27}$. As shown in Fig. 2c, the pristine $\mathrm{MoS}_{2}$ samples were flower-like nanospheres with diameters of $\sim 1-2 \mu \mathrm{m}$. Wrinkles and scrolling were observed in the transmission electron microscopy (TEM) images (Fig. 2d), indicating the extremely small thickness of the 2D structure. Scanning electron microscope (SEM) (Fig. 2e) revealed the presence of $\mathrm{Fe}_{2} \mathrm{O}_{3}$ nanoparticles (well below $20 \mathrm{~nm}$ in size according to TEM, Fig. 2f). As shown in Fig. 2g, $\mathrm{Fe}_{2} \mathrm{O}_{3}$ nanoparticles were dispersed, and a few $\mathrm{Fe}_{2} \mathrm{O}_{3}$ nanoparticle aggregations were present on the $\mathrm{MoS}_{2}$ NF. The highresolution TEM image in Fig. $2 \mathrm{~h}$ provided further insight regarding the morphology and microstructure of $\mathrm{MoS}_{2} /$ $\mathrm{Fe}_{2} \mathrm{O}_{3}$. The $d$-spacing of the lattice stripes of $\mathrm{Fe}_{2} \mathrm{O}_{3}$ was $0.252 \mathrm{~nm}$, which corresponded to the $(001)$ lattice plane of hexagonal $\mathrm{Fe}_{2} \mathrm{O}_{3}{ }^{28}$. In regard to the $\mathrm{MoS}_{2} / \mathrm{Fe}_{2} \mathrm{O}_{3} \mathrm{NCs}$, the lattice spacing was $0.624 \mathrm{~nm}$, corresponding to the hexagonal $\mathrm{MoS}_{2}$ (002) plane. In addition, the boundary between $\mathrm{Fe}_{2} \mathrm{O}_{3}$ and $\mathrm{MoS}_{2}$ was clearly observed, indicating that a heterojunction was formed between these two components. The regions with different colors in Fig. 2j-m correspond to $\mathrm{S}, \mathrm{Mo}, \mathrm{Fe}$, and $\mathrm{O}$, and the elemental distribution in $\mathrm{MoS}_{2} / \mathrm{Fe}_{2} \mathrm{O}_{3}$ was uniform.

$\mathrm{X}$-ray photoelectron spectroscopy (XPS) was performed to analyze the electronic states and chemical composition of the $\mathrm{MoS}_{2} / \mathrm{Fe}_{2} \mathrm{O}_{3} \mathrm{NCs}$ (Fig. 3). The survey scan spectra of pristine $\mathrm{MoS}_{2}, \mathrm{Fe}_{2} \mathrm{O}_{3}$, and $\mathrm{MoS}_{2} / \mathrm{Fe}_{2} \mathrm{O}_{3}$ NCs are presented in Fig. 3a, which confirmed the coexistence of Fe $2 p$, O $1 s$, Mo $3 p$, and S $2 p$ in the hybrid. The Mo $3 d$ spectra exhibited three peaks for pristine $\mathrm{MoS}_{2}$, but after forming the $\mathrm{MoS}_{2} / \mathrm{Fe}_{2} \mathrm{O}_{3} \mathrm{NCs}$, four peaks appeared in Fig. 3b. The peaks at 235.8, 232.6, 229.4, and $226.5 \mathrm{eV}$ corresponded to $\mathrm{Mo}^{6+} 3 d_{3 / 2}, \mathrm{Mo}^{4+} 3 d_{3 / 2}, \mathrm{Mo}^{4+} 3 d_{5 / 2}$, and S $2 s$, respectively. A small portion of $\mathrm{Mo}^{4+}$ was oxidized into $\mathrm{Mo}^{6+}$ during the reaction, confirming that $\mathrm{Fe}_{2} \mathrm{O}_{3}$ was successfully recombined with $\mathrm{MoS}_{2}$. In Fig. 3b, the two peaks at 163.3 and $162.2 \mathrm{eV}$ could be assigned to the doublet $\mathrm{S} 2 p_{1 / 2}$ and $\mathrm{S} 2 p_{3 / 2}$ orbitals of divalent sulfide ions $\left(\mathrm{S}^{2-}\right)$, respectively, in agreement with the formation of the $\mathrm{MoS}_{2}$ nanostructure ${ }^{29}$. The Fe $2 p$ spectrum exhibited two peaks at 710.4 and $723.7 \mathrm{eV}$ (Fig. 3c), corresponding to the $\mathrm{Fe} 2 p_{3 / 2}$ and $\mathrm{Fe} 2 p_{1 / 2}$ components of $\gamma-\mathrm{Fe}_{2} \mathrm{O}_{3}{ }^{30}$. XPS peak shifts were also observed in the $\mathrm{MoS}_{2} / \mathrm{Fe}_{2} \mathrm{O}_{3}$ composites compared with pristine $\mathrm{Fe}_{2} \mathrm{O}_{3}$, confirming the successful formation of an electronically coupled interface between $\mathrm{MoS}_{2}$ and $\mathrm{Fe}_{2} \mathrm{O}_{3}{ }^{31,32}$. The high-resolution $\mathrm{O} 1 s$ spectrum of the $\mathrm{MoS}_{2} / \mathrm{Fe}_{2} \mathrm{O}_{3} \mathrm{NCs}$ is shown in Fig. 3d. The spectrum could be deconvoluted into two components: the peak at $529.3 \mathrm{eV}$ was related to 

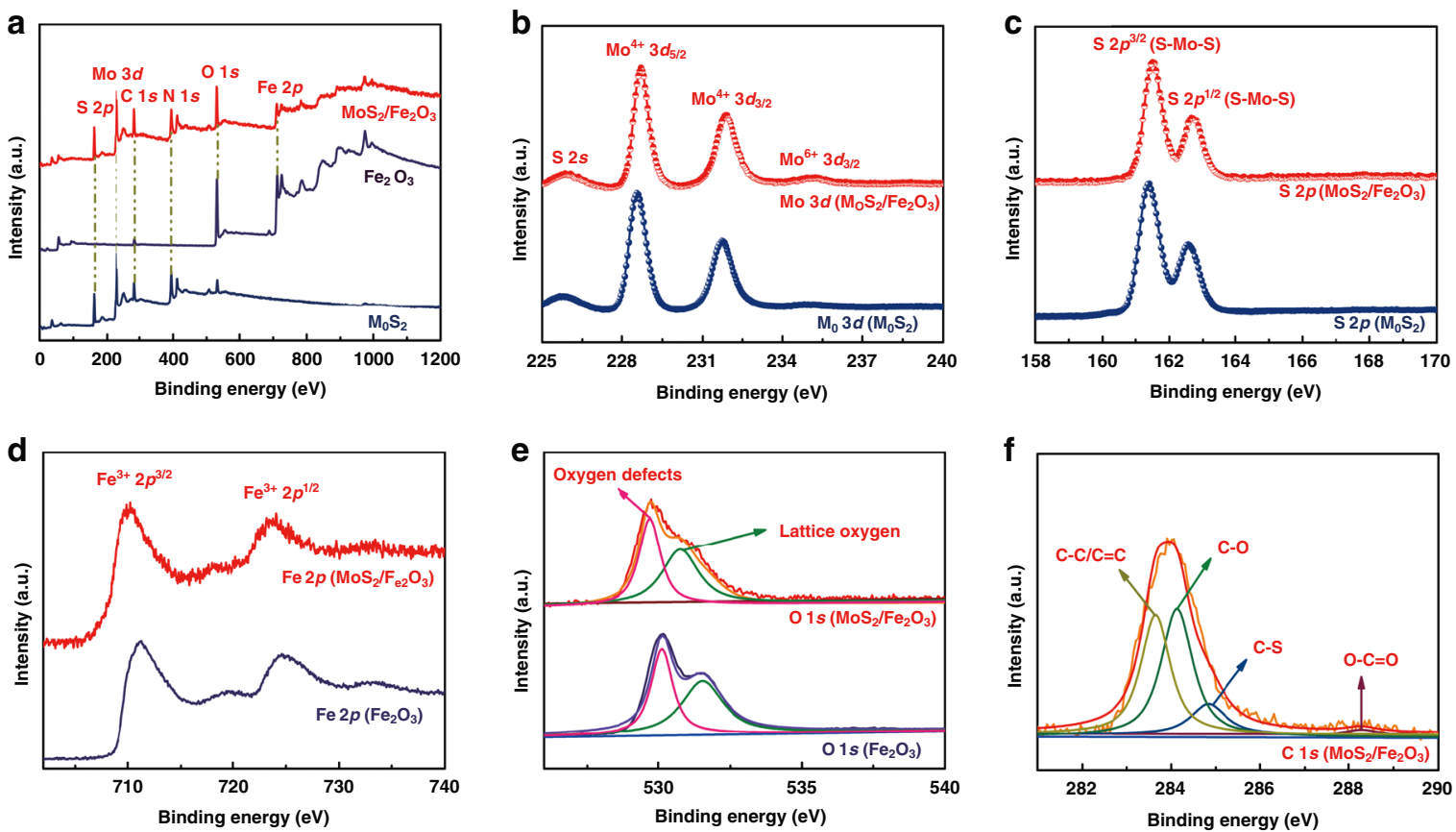

Fig. 3 The electronic states and chemical composition of the $\mathrm{MoS}_{2} / \mathrm{Fe}_{2} \mathrm{O}_{3}$ NCs. a XPS survey spectra for $\mathrm{MoS}_{2} / \mathrm{Fe}_{2} \mathrm{O}_{3} \mathrm{NCS}_{1} \mathrm{MOS}_{2}$, and Fe $\mathrm{O}_{3}$. XPS spectra of $\mathrm{MoS}_{2} / \mathrm{Fe}_{2} \mathrm{O}_{3}$ and $\mathrm{MoS}_{2}$ : b Mo 3d, c S 2p, d Fe 2p, e O $1 s$, and $\mathbf{f} \mathrm{C}$ 1s of the $\mathrm{MoS}_{2} / \mathrm{Fe}_{2} \mathrm{O}_{3} \mathrm{NCs}$.

the binding energy of $\mathrm{Fe}-\mathrm{O}$ in $\mathrm{Fe}_{2} \mathrm{O}_{3}$ caused by lattice $\mathrm{O}$, and the peak at $530.7 \mathrm{eV}$ was related to the $\mathrm{O}^{2-}$ ions in the anoxic region ${ }^{33}$. Specifically, the $\mathrm{C} 1 \mathrm{~s}$ spectrum (Fig. 3f) was deconvoluted into four peaks at 283.7, 284.1, 284.9, and $288.3 \mathrm{eV}$ corresponding to the $\mathrm{C}-\mathrm{C} / \mathrm{C}=\mathrm{C}$, $\mathrm{C}-\mathrm{O}, \mathrm{C}-\mathrm{S}$, and $\mathrm{O}-\mathrm{C}=\mathrm{O}$ bonds, respectively ${ }^{34}$.

\section{SERS enhancement and reusability of $\mathrm{MoS}_{2} / \mathrm{Fe}_{2} \mathrm{O}_{3} \mathrm{NCs}$ for BPA detection}

Herein, $p$-aminobenzene sulfonic acid, $\mathrm{NaNO}_{3}$, and $\mathrm{Na}_{2} \mathrm{CO}_{3}$ as Pauly's reagent were added in the BPA detection test to enhance the adhesion of BPA on the surface of the $\mathrm{MoS}_{2} / \mathrm{Fe}_{2} \mathrm{O}_{3}$ NCs. As shown in Fig. 4, $p$-aminobenzene sulfonic acid, $\mathrm{NaNO}_{3}$ and $\mathrm{Na}_{2} \mathrm{CO}_{3}$, were all low Raman scattering active molecules; therefore, their addition had almost no effect on BPA detection. To confirm that $\mathrm{MoS}_{2} / \mathrm{Fe}_{2} \mathrm{O}_{3}$ had excellent SERS properties, SERS spectra of BPA absorbed on $\mathrm{MoS}_{2} / \mathrm{Fe}_{2} \mathrm{O}_{3}$ at various concentrations ranging from $10^{-4}$ to $10^{-9} \mathrm{M}$ were obtained, as shown in Fig. 5a. These results indicated that as the concentration of BPA decreased, the intensity of the Raman peaks decreased. The characteristic peak of BPA at $1124 \mathrm{~cm}^{-1}$ was observed at concentrations as low as $10^{-9} \mathrm{M}$, indicating that the $\mathrm{MoS}_{2} / \mathrm{Fe}_{2} \mathrm{O}_{3} \mathrm{NCs}$ had a high sensitivity. The intensity of the peak at $1124 \mathrm{~cm}^{-1}$ was correlated with the BPA concentration; thus, we used it for further quantitative analysis. Figure $5 \mathrm{~b}$ shows the direct proportionality between the BPA concentration, in the range of $10^{-4}-10^{-9} \mathrm{M}$, and the normalized Raman signal intensity. The linear equation is as follows:

$$
\log \left(I_{1124}\right)=(1624 \pm 106) \log C_{\mathrm{BPA}}+(17,076 \pm 746)
$$

with a squared correlation coefficient of $R^{2}=0.97$. The stability of the substrate is an important factor that must be considered. As shown in Fig. 5c, the SERS spectrum of the $\mathrm{MoS}_{2} / \mathrm{Fe}_{2} \mathrm{O}_{3} \mathrm{NCs}$ substrate hardly changed over time; thus, the $\mathrm{MoS}_{2} / \mathrm{Fe}_{2} \mathrm{O}_{3} \mathrm{NCs}$ could be stored for at least 3 months under ambient conditions.

As shown in Fig. 5d, the hysteresis loop of the $\mathrm{MoS}_{2} /$ $\mathrm{Fe}_{2} \mathrm{O}_{3}$ NCs indicated excellent superparamagnetic behavior. The saturation magnetization $\left(M_{\mathrm{s}}\right)$ value of the $\mathrm{MoS}_{2} / \mathrm{Fe}_{2} \mathrm{O}_{3} \mathrm{NCs}(0.46 \mathrm{emu} / \mathrm{g})$ was higher than that of $\mathrm{Fe}_{2} \mathrm{O}_{3}$ alone. This good magnetic property completely satisfied the requirements for magnetic separation. The uniformly dispersed $\mathrm{MoS}_{2} / \mathrm{Fe}_{2} \mathrm{O}_{3} \mathrm{NCs}$ quickly separated from the solution and formed aggregates within $22 \mathrm{~s}$ when external magnets were used. Conversely, when the magnets were removed, the agglomerated $\mathrm{MoS}_{2} / \mathrm{Fe}_{2} \mathrm{O}_{3}$ quickly redistributed into the solution via slight shaking, as shown in the inset of Fig. 5d. In addition, we measured the magnetization of the $\mathrm{MoS}_{2} / \mathrm{Fe}_{2} \mathrm{O}_{3} \mathrm{NCs}$ after 3 months and found that the $M_{\mathrm{s}}$ value hardly changed (from 0.46 to $0.52 \mathrm{emu} / \mathrm{g}$ ). Hence, we concluded that $\mathrm{MoS}_{2} / \mathrm{Fe}_{2} \mathrm{O}_{3} \mathrm{NCs}$ were highly stable at room temperature and atmospheric pressure. To test the reusability of the $\mathrm{MoS}_{2} / \mathrm{Fe}_{2} \mathrm{O}_{3} \mathrm{NCs}$, we repeated the SERS experiment five times with the same 

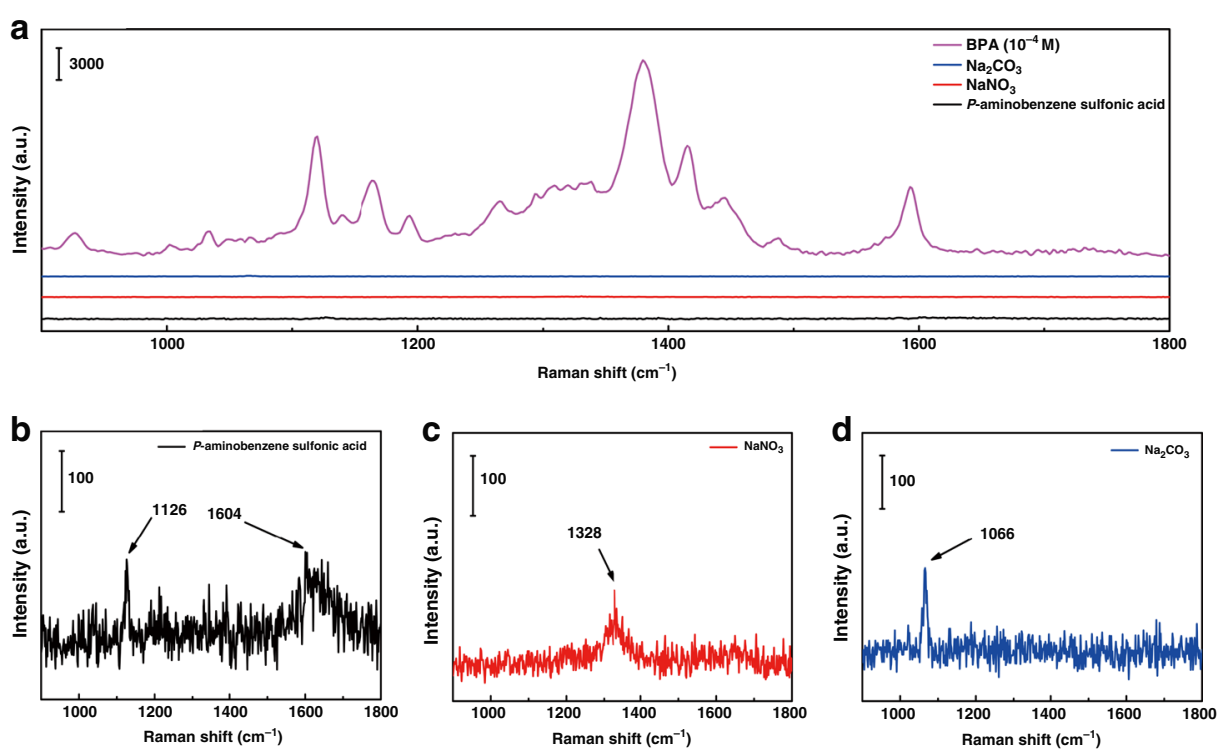

Fig. 4 Detection of Pauly's reagent. a SERS spectra of BPA, p-aminobenzene sulfonic acid, $\mathrm{NaNO}_{3}$, and $\mathrm{Na}_{2} \mathrm{CO}_{3}$ adsorbed on the $\mathrm{MoS}_{2} / \mathrm{Fe} \mathrm{O}_{3} \mathrm{NCs}$. b SERS spectrum of $p$-aminobenzene sulfonic acid adsorbed on the $\mathrm{MoS}_{2} / \mathrm{Fe}_{2} \mathrm{O}_{3} \mathrm{NCs}$. c SERS spectra of $\mathrm{NaNO}_{3}$ adsorbed on the $\mathrm{MoS}_{2} / \mathrm{Fe} \mathrm{O}_{3} \mathrm{NCs}$. d SERS spectrum of $\mathrm{Na}_{2} \mathrm{CO}_{3}$ adsorbed on the $\mathrm{MoS}_{2} / \mathrm{Fe}_{2} \mathrm{O}_{3} \mathrm{NCs}$.

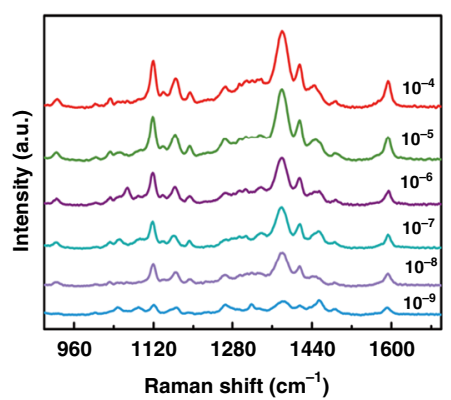

d



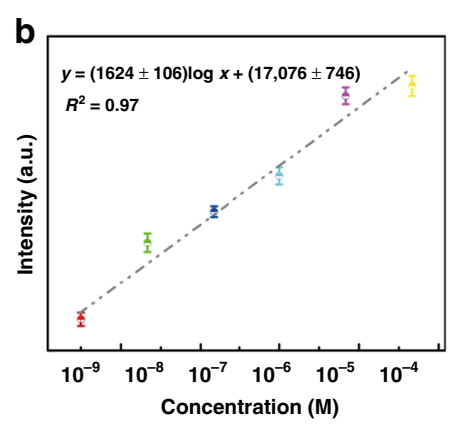


f

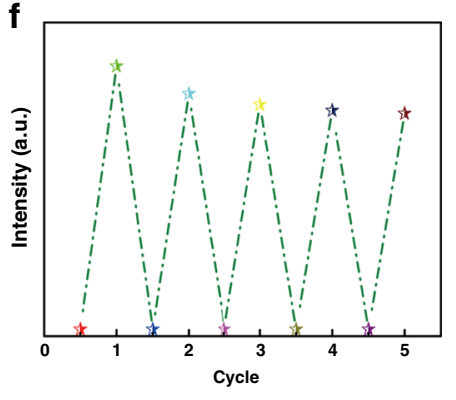

Fig. 5 Sensitivity, stability, and reproducibility of $\mathrm{MoS}_{2} / \mathrm{Fe}_{2} \mathrm{O}_{3} \mathrm{NCs}$. a SERS spectra of $\mathrm{MoS}_{2} / \mathrm{Fe}_{2} \mathrm{O}_{3} \mathrm{NCS}$ incubated with a BPA aqueous solution at various concentrations. $\mathbf{b}$ Calibration curve for BPA at $1124 \mathrm{~cm}^{-1}$. c SERS spectra of the $10^{-4} \mathrm{M} \mathrm{BPA}$ aqueous solution based on the $\mathrm{MoS}_{2} / \mathrm{Fe}_{2} \mathrm{O}_{3}$ substrate collected at different shelf times. $\mathbf{d}$ Room temperature magnetic hysteresis curves of the $\mathrm{MoS}_{2} / \mathrm{Fe}_{2} \mathrm{O}_{3} \mathrm{NCs}$ and MoS $2 \mathrm{NFs}$. The inset shows the water dispersibility and magnetic separability of the $\mathrm{MoS}_{2} / \mathrm{Fe}_{2} \mathrm{O}_{3} \mathrm{NCS}$. e SERS spectra of BPA after the self-cleaning test. $\mathbf{f}$ Corresponding normalized Raman intensities of $1385 \mathrm{~cm}^{-1}$ when the SERS substrate was recycled five times for the detection of $10^{-4} \mathrm{M} B P A$.

sample. After each experiment, the $\mathrm{MoS}_{2} / \mathrm{Fe}_{2} \mathrm{O}_{3} \mathrm{NCs}$ were separated from the solution using a magnet. Figure $5 \mathrm{e}$ shows the SERS spectrum of a $\mathrm{MoS}_{2} / \mathrm{Fe}_{2} \mathrm{O}_{3}$ substrate that was reused after absorbing the same concentration of BPA; the results indicated that the substrate had good reproducibility. As shown in Fig. 5f, the $\mathrm{MoS}_{2} / \mathrm{Fe}_{2} \mathrm{O}_{3} \mathrm{NC}$ 
substrate had excellent SERS activity even after five recycling runs. Although the average Raman intensity decreased slightly, it satisfied the qualitative testing requirements for BPA. These results indicate that the $\mathrm{MoS}_{2} / \mathrm{Fe}_{2} \mathrm{O}_{3} \mathrm{NCs}$ were reproducible and show promise as reusable substrate materials.

\section{Detection in "real-world" samples}

To evaluate the application of the $\mathrm{MoS}_{2} / \mathrm{Fe}_{2} \mathrm{O}_{3} \mathrm{NCs}$, "real-world" samples (lake water and milk) were chosen for detection. As shown in Fig. 6, the characteristic $\mathrm{CH}$ wagging peak of BPA at $1124 \mathrm{~cm}^{-1}$ was observed at concentrations as low as $10^{-7} \mathrm{M}$ for these samples, indicating that the $\mathrm{MoS}_{2} / \mathrm{Fe}_{2} \mathrm{O}_{3}$ NCs could be used for the practical and rapid detection of BPA.

\section{Photocatalytic activity of $\mathrm{MoS}_{2} / \mathrm{Fe}_{2} \mathrm{O}_{3} \mathrm{NCs}$}

The catalytic properties of the pristine $\mathrm{MoS}_{2} \mathrm{NFs}$, $\mathrm{Fe}_{2} \mathrm{O}_{3}$ NPs, and $\mathrm{MoS}_{2} / \mathrm{Fe}_{2} \mathrm{O}_{3} \mathrm{NCs}$ were evaluated by performing BPA degradation experiments under UV irradiation. The BPA degradation results for the $\mathrm{MoS}_{2}$

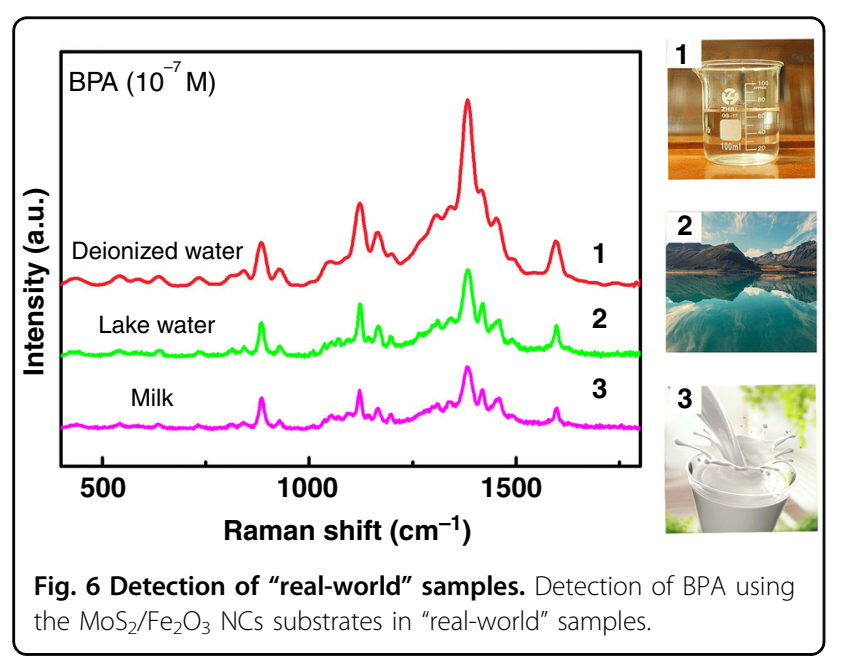

NFs, $\mathrm{Fe}_{2} \mathrm{O}_{3}$ NPs, and $\mathrm{MoS}_{2} / \mathrm{Fe}_{2} \mathrm{O}_{3}$ NCs samples under UV light are presented in Fig. $7 \mathrm{a}-\mathrm{c}$, respectively. For all catalysts, the intensity of the main absorption peak decreased with increasing irradiation time. After $50 \mathrm{~min}$ of UV irradiation, the degradation rates of the two pristine photocatalysts $\left(\mathrm{MoS}_{2} \mathrm{NFs}\right.$ and $\left.\mathrm{Fe}_{2} \mathrm{O}_{3} \mathrm{NPs}\right)$ were only $\sim 40 \%$ and $48 \%$, respectively. Surprisingly, the photocatalytic activity was significantly increased in the presence of the $\mathrm{MoS}_{2} / \mathrm{Fe}_{2} \mathrm{O}_{3} \mathrm{NCs}$ catalyst; in this case, $>92 \%$ of the present BPA was decomposed after $50 \mathrm{~min}$ of irradiation, as shown in Fig. 7c. This degradation rate is significantly higher than those observed with the $\mathrm{MoS}_{2}$ NFs and $\mathrm{Fe}_{2} \mathrm{O}_{3}$ NPs.

A related graph showing the dependence of the BPA degradation efficiencies of the $\mathrm{MoS}_{2} / \mathrm{Fe}_{2} \mathrm{O}_{3} \mathrm{NCs}$ and other catalysts on the UV irradiation time is presented in Fig. 8a. We define the degradation efficiency as $C / C_{0}$, where $C_{0}$ represents the initial BPA concentration $(\mathrm{mg} / \mathrm{L})$ and $C$ represents the BPA concentration after the reaction $(\mathrm{mg} / \mathrm{L})$. As shown in Fig. 8a, the $\mathrm{MoS}_{2} / \mathrm{Fe}_{2} \mathrm{O}_{3}$ $\mathrm{NCs}$ had better photocatalytic activity than the other catalysts. The photocatalytic efficiency of $\mathrm{MoS}_{2} / \mathrm{Fe}_{2} \mathrm{O}_{3}$ $\mathrm{NCs}$ was as high as 0.02 , which was higher than that of pure $\mathrm{MoS}_{2}$ (0.01) and $\mathrm{Fe}_{2} \mathrm{O}_{3}$ (0.008). Thus, the $\mathrm{MoS}_{2} /$ $\mathrm{Fe}_{2} \mathrm{O}_{3} \mathrm{NCs}$ has great potential for use in wastewater treatments. Before light irradiation, the photocatalyst and BPA solution were stirred under dark conditions for 10 min to attain an adsorption equilibrium. During this period, the concentration of BPA decreased because of the adsorption of BPA molecules on the photocatalysts. We used the pseudo-first-order mode to investigate the reaction kinetics of BPA degradation. The simplified equation is:

$$
-\ln \left(C / C_{0}\right)+k t
$$

where $k$ represents the apparent first-order reaction rate constant ${ }^{35}$. Figure $8 \mathrm{~b}$ shows the relationship
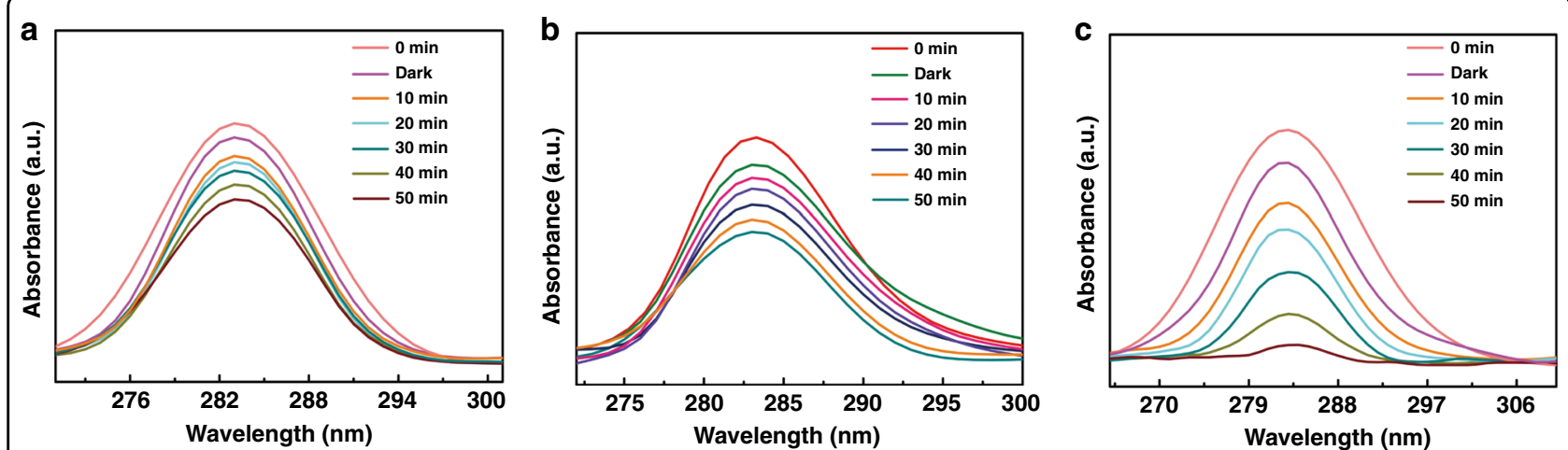

Fig. 7 Photocatalytic activity of $\mathrm{MoS}_{2} / \mathrm{Fe}_{2} \mathrm{O}_{3} \mathbf{N C s}$. UV-vis absorption spectra of a BPA solution in the presence of a MoS $2 \mathrm{NFs}_{2} \mathbf{b} \mathrm{Fe}_{2} \mathrm{O}_{3} \mathrm{NPS}$, and c $\mathrm{MoS}_{2} / \mathrm{Fe}_{2} \mathrm{O}_{3} \mathrm{NCS}$. 

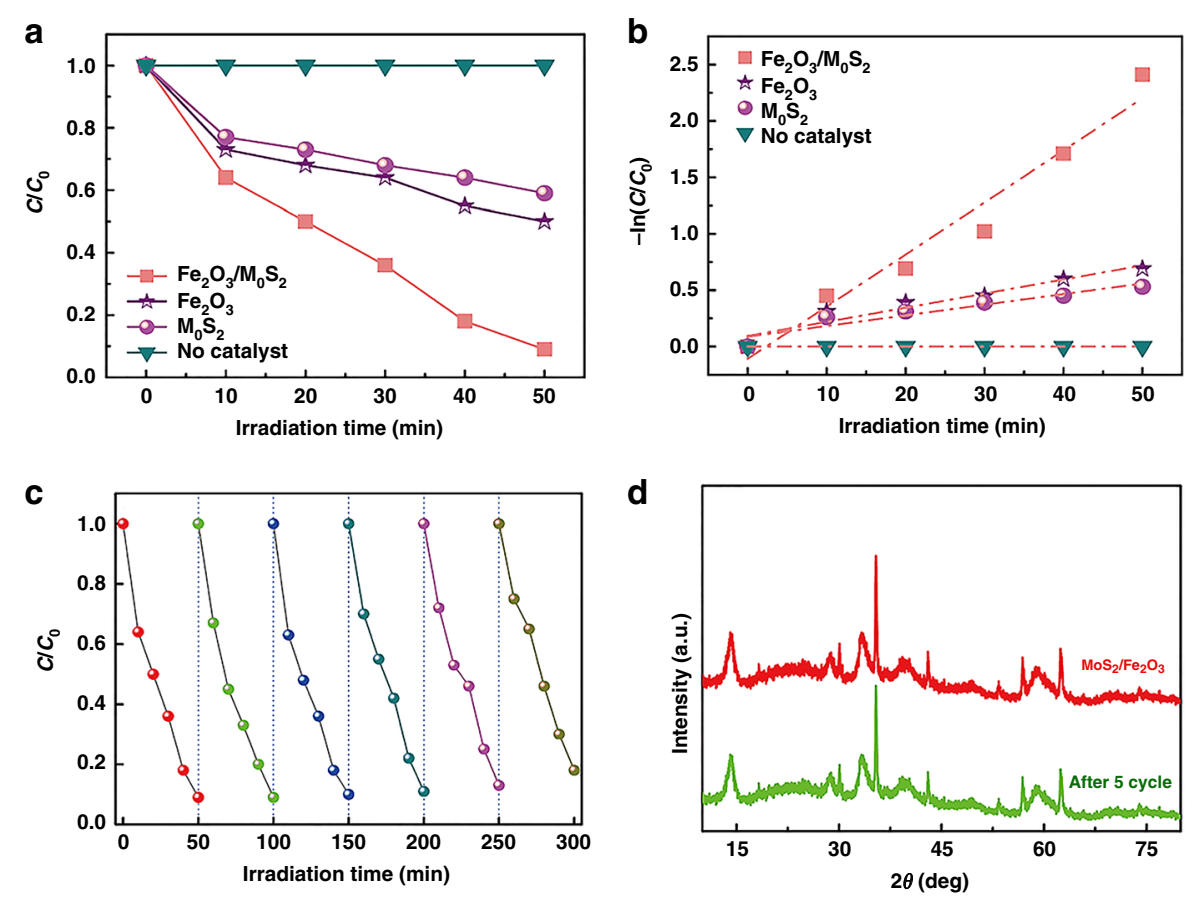

Fig. 8 Photocatalytic activity and stable photoactivity of $\mathrm{MoS}_{2} / \mathrm{Fe}_{2} \mathrm{O}_{3} \mathrm{NCs}$. a Evolution of the relative concentrations $\left(C / C_{0}\right)$ of BPA with several photocatalysts as a function of irradiation time. $b$ Corresponding kinetic plots of the photocatalytic degradation of BPA with the selected photocatalysts. c Reusability and stable activity of the $\mathrm{MoS}_{2} / \mathrm{Fe}_{2} \mathrm{O}_{3} \mathrm{NCs}$ after being used for five cycles of the photocatalytic degradation of BPA. $\mathbf{d}$ XRD pattern of the $\mathrm{MoS}_{2} / \mathrm{Fe}_{2} \mathrm{O}_{3} \mathrm{NCs}$ before and after the fifth cycle.

between $-\ln \left(C / C_{0}\right)$ and the irradiation time for different photocatalysts. The curves could be fitted with a linear relationship, indicating that the degradation kinetics followed a typical first-order reaction. Using Eq. (1), we determined the apparent pseudo-firstorder rate constants for the different photocatalysts. The $k$ values of the pristine $\mathrm{Fe}_{2} \mathrm{O}_{3} \mathrm{NPs}, \mathrm{MoS}_{2} \mathrm{NFs}$, and $\mathrm{MoS}_{2} / \mathrm{Fe}_{2} \mathrm{O}_{3} \mathrm{NCs}$ were calculated to be $0.69,0.53$, and 2.41 , respectively. Stable photoactivity under UV light is critical for practical water treatment applications, particularly for composite materials that may lose their coating. We examined the loss of the BPA degradation activity of the $\mathrm{MoS}_{2} / \mathrm{Fe}_{2} \mathrm{O}_{3} \mathrm{NCs}$ by utilizing it for five consecutive cycles under UV light irradiation. No loss of activity was observed (Fig. 8c). As shown in Fig. 8d, the structure of the catalyst was not significantly changed after five consecutive photocatalytic degradation cycles, also suggesting that the $\mathrm{Fe}_{2} \mathrm{O}_{3}$ nanoparticles could slow down the photocorrosion of $\mathrm{MoS}_{2}$, thereby efficiently protecting $\mathrm{MoS}_{2}$. Generally, $\mathrm{MoS}_{2}$ is prone to photocorrosion due to oxidation of surface sulfions to sulfurs by photoexcited holes. Therefore, the $\mathrm{MoS}_{2} /$ $\mathrm{Fe}_{2} \mathrm{O}_{3}$ NCs exhibited high stability and excellent anti-photocorrosion properties, showing that this material has promise for use in environmental restoration applications.

\section{Mechanisms of SERS detection and photocatalysis}

When the $\mathrm{MoS}_{2} / \mathrm{Fe}_{2} \mathrm{O}_{3}$ heterojunction system was irradiated with UV light, $\mathrm{MoS}_{2}$ was excited, generating electron-hole pairs because of its narrow bandgap. The photoinduced electrons moved rapidly from the conduction band (CB) of $\mathrm{MoS}_{2}$ to that of $\mathrm{Fe}_{2} \mathrm{O}_{3}$, as shown in Fig. 9. In the $\mathrm{MoS}_{2} / \mathrm{Fe}_{2} \mathrm{O}_{3}$ NCs, the spatial separation of photoexcited holes and electrons extended the chargecarrier lifetime and hindered the recombination of electron-hole pairs, thereby enhancing the photocatalytic activity. Moreover, the selected transfer of holes from the valence band (VB) of $\mathrm{MoS}_{2}$ to $\mathrm{Fe}_{2} \mathrm{O}_{3}$ remarkably weakened the photocorrosion activity. After the carriers of $\mathrm{MoS}_{2}$ and $\mathrm{Fe}_{2} \mathrm{O}_{3}$ were generated, the free electrons accumulated in the $\mathrm{CB}$ of $\mathrm{Fe}_{2} \mathrm{O}_{3}$, while photoinduced holes were present in the $\mathrm{VB}$ of $\mathrm{MoS}_{2}$; thus, a high photocatalytic activity was obtained. Effective Z-type electron-hole pair separation and an effective transfer path were achieved, and a strong redox capacity of the photoexcited electron and holes was obtained in the $\mathrm{CB}$ and $\mathrm{VB}$, respectively, significantly improving the photocatalytic and SERS activity of the $\mathrm{MoS}_{2} / \mathrm{Fe}_{2} \mathrm{O}_{3} \mathrm{NC}$ heterojunction. Therefore, $\mathrm{Fe}_{2} \mathrm{O}_{3}$ not only acted as a protective shell for the $\mathrm{MoS}_{2}$ core by preventing the loss of sulfur but also constructed Z-type junctions that prolonged the lives of photogenerated electrons and holes, 


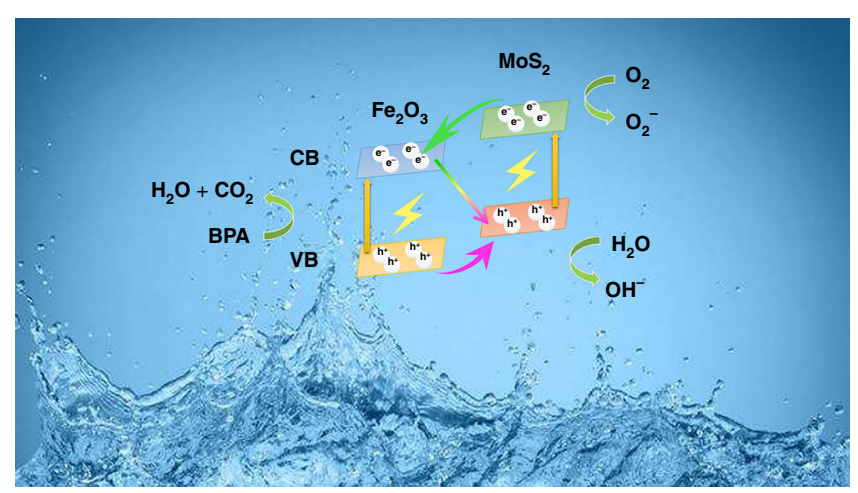

Fig. 9 SERS and photocatalytic mechanisms of $\mathrm{MoS}_{2} / \mathrm{Fe}_{2} \mathrm{O}_{3} \mathrm{NCs}$. Schematic illustration showing the proposed SERS and photocatalytic mechanisms of $\mathrm{MoS}_{2} / \mathrm{Fe}_{2} \mathrm{O}_{3} \mathrm{NCS}$.

which would significantly enhance the photocatalytic activity and stability. Another reason for the SERS enhancement was the semiconducting nature of $\mathrm{MoS}_{2}$. Because its surface had $\mathrm{S}$ atoms and polar covalent bonds (Mo-S) perpendicular to the surface, this dipole-dipole coupling significantly increased the intensity of the Raman peaks ${ }^{36}$. In addition, because of the large surfaceto-volume ratio, there was an abundance of active adsorption sites for gas molecules. The reactions involved in the photocatalytic process are summarized as follows:

$$
\begin{aligned}
& \mathrm{Mo} / \mathrm{Fe}_{2} \mathrm{O}_{3}+h \nu \rightarrow \mathrm{MoS}_{2}\left(h^{+}\right)+\mathrm{Fe}_{2} \mathrm{O}_{3}\left(\mathrm{e}^{-}\right) \\
& \mathrm{O}_{2}+\mathrm{e}^{-} \rightarrow \dot{\mathrm{O}}_{2}^{-} \\
& \dot{\mathrm{O}}_{2}^{-}+\dot{\mathrm{O}}_{2}^{-}+2 \mathrm{H}^{+} \rightarrow \mathrm{H}_{2} \mathrm{O}_{2}+\mathrm{O}_{2} \\
& \mathrm{H}_{2} \mathrm{O}_{2}+\mathrm{e}^{-}+h \nu \rightarrow \dot{\mathrm{O}} \mathrm{H}+\mathrm{OH}^{-} \\
& \mathrm{BPA}+\dot{\mathrm{O}} \rightarrow \mathrm{CO}_{2}+\mathrm{H}_{2} \mathrm{O}+\operatorname{degraded} \mathrm{BPA}
\end{aligned}
$$

\section{Conclusion}

In summary, a multifunctional material was fabricated by simply depositing $\mathrm{Fe}_{2} \mathrm{O}_{3}$ NPs onto $\mathrm{MoS}_{2}$ NFs, which significantly improved its photocatalytic properties and ability to be used as a SERS substrate. In addition, the $\mathrm{MoS}_{2} / \mathrm{Fe}_{2} \mathrm{O}_{3}$ NCs were successfully recycled. This study is the first to report $\mathrm{MoS}_{2} / \mathrm{Fe}_{2} \mathrm{O}_{3} \mathrm{NCs}$ used as SERS substrates for BPA detection. The $\mathrm{MoS}_{2} / \mathrm{Fe}_{2} \mathrm{O}_{3} \mathrm{NCs}$ had a detection limit of $1 \times 10^{-9} \mathrm{M}$, along with exhibiting excellent stability. The prepared $\mathrm{MoS}_{2} / \mathrm{Fe}_{2} \mathrm{O}_{3}$ NCs had higher photocatalytic activity than the $\mathrm{MoS}_{2} \mathrm{NFs}$ and $\mathrm{Fe}_{2} \mathrm{O}_{3}$ NPs alone. The enhanced photocatalytic activity and SERS activity were attributed to the efficient separation and transfer of electron-hole pairs by the Z-scheme heterojunction system. Therefore, as efficient multifunctional catalysts, $\mathrm{MoS}_{2} /$ $\mathrm{Fe}_{2} \mathrm{O}_{3} \mathrm{NCs}$ are expected to not only replace metal catalysts for removing organic matter from water and the environment but also pave the way for SERS applications, thereby introducing new methods for chemical and medical detection and for environmental monitoring.

\section{Materials and methods MoS2 NF preparation}

First, $0.5 \mathrm{~g} \mathrm{H}_{4} \mathrm{MoNa}_{2} \mathrm{O}_{6}$ and $0.7 \mathrm{~g} \mathrm{CH}_{4} \mathrm{~N}_{2} \mathrm{~S}$ were mixed and stirred in $70 \mathrm{~mL}$ of ultrapure water. Then, $0.5 \mathrm{~g}$ $\mathrm{C}_{6} \mathrm{H}_{8} \mathrm{O}_{7} \cdot \mathrm{H}_{2} \mathrm{O}$ was added until complete dissolution was achieved. The sample was transferred into an $80 \mathrm{~mL}$ Teflon-lined hydrothermal autoclave reactor and then placed in a drying box at $240{ }^{\circ} \mathrm{C}$ for $24 \mathrm{~h}$. Next, the reaction products were centrifuged with alcohol and ultrapure water and dried at $70^{\circ} \mathrm{C}$.

\section{$\mathrm{MoS}_{2} / \mathrm{Fe}_{2} \mathrm{O}_{3} \mathrm{NC}$ preparation}

First, $0.2 \mathrm{~g}$ of $\mathrm{MoS}_{2}$ powder, $0.5 \mathrm{~g}$ of $\mathrm{H}_{18} \mathrm{FeN}_{3} \mathrm{O}_{18}$, and $0.7 \mathrm{~g}$ of $\mathrm{H}_{2} \mathrm{NCONH}_{2}$ were mixed in $70 \mathrm{~mL}$ of ultrapure water. Then, $0.02 \mathrm{~g}$ of $\mathrm{C}_{18} \mathrm{H}_{29} \mathrm{NaO}_{3} \mathrm{~S}$ were well dispersed in the liquid mixture, stirred in a $60^{\circ} \mathrm{C}$ water bath for $35 \mathrm{~min}$, transferred to an $80 \mathrm{~mL}$ reactor, and finally placed in a drying box at $90^{\circ} \mathrm{C}$ for $12 \mathrm{~h}$. The $\mathrm{MoS}_{2} / \mathrm{Fe}_{2} \mathrm{O}_{3} \mathrm{NCs}$ were washed with absolute ethanol and water to remove possible residuals. The solid powder solid was placed in a drying box and kept dry at $80^{\circ} \mathrm{C}$.

\section{Characterizations}

XPS (ESCALAB250X, Thermo Scientific) and X-ray diffraction (XRD, D/Max 3C, Rigaku) were used to study the structural quality. TEM (JEM-2100HR, JEOL) and SEM (JSM-7800F, JEOL) were used to characterize the morphology of the samples. UV-visible absorption spectroscopy (UV-3600, Shimadzu Corporation) and a vibrating sample magnetometer (7407, Lake Shore) were used to characterize the optical and magnetic properties of the samples. Raman spectra were obtained with an $\mathrm{Ar}^{+}$-ion laser (inVia Raman, Renishaw). 


\section{SERS experiments of BPA}

We used the coupling reaction of BPA with Pauly's reagents ( $p$-aminobenzene sulfonic acid, $\mathrm{HCl}, \mathrm{NaNO}_{3}$, and $\left.\mathrm{Na}_{2} \mathrm{CO}_{3}\right)$ to enhance the adhesion of BPA onto the surface of the SERS substrate materials. Please refer to our previous report for the detailed process ${ }^{37}$.

\section{SERS experiments of BPA in milk and lake water}

Real milk contains fat, protein, vitamins, and other organic ingredients that can interfere with the detection of BPA. Therefore, it is necessary to pretreat the milk sample with BPA. The process is as follows. First, methanol $(7 \mathrm{~mL})$ and water $(3 \mathrm{~mL})$ were mixed and added to the milk sample (containing $10^{-7} \mathrm{M} \mathrm{BPA}, 4 \mathrm{~mL}$ ), and then the mixture was sonicated and centrifuged at 10,000 r.p.m. for $3 \mathrm{~min}$. The upper supernatant was extracted and then dried. This extract was collected in another centrifuge tube and mixed with methanol and water, with the above sonication and centrifugation process being repeated. Finally, the extract was filtered by membrane filters $(0.45$ and $0.22 \mu \mathrm{m})$ for the SERS test. The procedures for the detection and data analysis were the same as those for detecting BPA in water.

We collected lake water from a local source (South Lake in Changchun City). Lake water samples with BPA added were filtered by membrane filters $(0.45$ and $0.22 \mu \mathrm{m})$ before the detection test to avoid interference from other impurities. The test process was consistent with that described above.

\section{Photodegradation experiments}

In the degradation process, circulating water was used to ensure that all the tests were performed at room temperature. The photodegradation of BPA under UV light was performed to assess the activity of photocatalysts. One hundred milliliters of an aqueous solution was prepared with $0.001 \mathrm{~g}$ of BPA and $0.05 \mathrm{~g}$ of $\mathrm{Fe}_{2} \mathrm{O}_{3} /$ $\mathrm{MoS}_{2}, \mathrm{MoS}_{2}$, or $\mathrm{Fe}_{2} \mathrm{O}_{3} \mathrm{NCs}$. The test solution was stirred magnetically in a $100-\mathrm{mL}$ beaker. The sample was kept in a dark room for $10 \mathrm{~min}$ for the adsorption of BPA molecules on the photocatalysts before being subjected to UV irradiation. During the experiment, the samples were taken at specified times. After each sampling, the catalyst was separated via centrifugation for testing.

\section{Acknowledgements}

This work was financially supported by the National Natural Science Foundation of China (Nos. 61675090, 21776110, and 61705020), the National Youth Foundation of China (Nos. 61405072, 61704065, and 61705078), the Program for the Development of Science and Technology Jilin Province (Nos. 20200301043RQ, 20200201022JC, 20190103002JH, and 20180520179JH), the Thirteenth Five-Year Program for Science and Technology of Education Department of Jilin Province (Grant Numbers JJKH20200418KJ, JJKH20191018K, JJKH20191022KJ, and JJKH20190550KJ), Tianjin Natural Science Foundation (Grant Number 16JCYBJC41400).

\section{Author details}

'Key Laboratory of Functional Materials Physics and Chemistry of the Ministry of Education, Jilin Normal University, 130103 Changchun, People's Republic of
China. ${ }^{2}$ National Demonstration Centre for Experimental Physics Education, Jilin Normal University, 136000 Siping, People's Republic of China. ${ }^{3}$ Key Laboratory of Preparation and Application of Environmental Friendly Materials, Jilin Normal University, Ministry of Education, 130103 Changchun, People's Republic of China. ${ }^{4}$ College of Science, Changchun University, 130022 Changchun, People's Republic of China. ${ }^{5}$ Changchun Institute of Optics, Fine Mechanics and Physics, Chinese Academy of Sciences, 130103 Changchun, People's Republic of China

\section{Author contributions}

M.H. and Y.Q. put forward ideas. M.H. conducted the experiment and wrote the original draft preparation. S.Y., R.S., H.L., and J.Y. participated in the discussion of the experimental data. L.C. provided good advice. M.G. designed the project and also revised and edited the manuscript.

\section{Conflict of interest}

The authors declare that they have no conflict of interest.

Received: 6 June 2020 Revised: 6 September 2020 Accepted: 12 October 2020

Published online: 28 December 2020

\section{References}

1. Alsbaiee, A. et al. Rapid removal of organic micropollutants from water by a porous $\beta$-cyclodextrin polymer. Nature 529, 190-194 (2016).

2. Tao, F. F. \& Salmeron, M. In situ studies of chemistry and structure of materials in reactive environments. Science 331, 171-174 (2011).

3. Sarwar, M. et al. Smart-phone, paper-based fluorescent sensor for ultra-low inorganic phosphate detection in environmental samples. Microsyst. Nanoeng. 5, 56 (2019).

4. Guan, Y. \& Sun, B. Detection and extraction of heavy metal ions using paperbased analytical devices fabricated via atom stamp printing. Microsyst. Nanoeng. 6, 14 (2020)

5. Le Pivert, M. et al. Direct growth of $\mathrm{ZnO}$ nanowires on civil engineering materials: smart materials for supported photodegradation. Microsyst. Nanoeng. 5, 57 (2019).

6. Yousefi, N., Lu, X. L., Elimelech, M. \& Tufenkji, N. Environmental performance of graphene-based 3D macrostructures. Nat. Nanotechnol. 14, 107-119 (2019).

7. Kim, J. et al. Uniaxially crumpled graphene as a platform for guided myotube formation. Microsyst. Nanoeng. 5, 53 (2019).

8. Wang, Y. et al. Low sample volume origami-paper-based graphene-modified aptasensors for label-free electrochemical detection of cancer biomarkerEGFR. Microsyst. Nanoeng. 6, 32 (2020).

9. Shan, H. Y. et al. Direct observation of ultrafast plasmonic hot electron transfer in the strong coupling regime. Light Sci. Appl. 8, 9 (2019).

10. Sanjay, B. \& Vikas, B. Interfacial nondegenerate doping of $\mathrm{MoS}_{2}$ and other twodimensional semiconductors. ACS Nano 9, 2227-2230 (2015).

11. Shi, Y. et al. Hot electron of Au nanorods activates the electrocatalysis of hydrogen evolution on $\mathrm{MoS}_{2}$ nanosheets. J. Am. Chem. Soc. 137, 7365-7370 (2015).

12. Kang, $Y$. et al. Plasmonic hot electron induced structural phase transition in a $\mathrm{MoS}_{2}$ monolayer. Adv. Mater. 26, 6467-6471 (2014).

13. Yao, J. C. et al. AgNPs decorated Mg-doped ZnO nanobroccolis heterostructure with dramatic SERS activity. J. Mater. Chem. C 7, 8199-8208 (2019).

14. Liu, K. et al. Porous Au-Ag nanospheres with high-density and highly accessible hotspots for SERS analysis. Nano Lett. 16, 3675-3681 (2016).

15. Wang, Y. Q. et al. SERS tags: novel optical nanoprobes for bioanalysis. Chem Rev. 113, 1391-1428 (2013).

16. Song, Z. L. et al. Alkyne-functionalized superstable graphitic silver nanoparticles for raman imaging. J. Am. Chem. Soc. 136, 13558-13561 (2014).

17. Phan-Quang, G. C., Lee, H. K., Phang, I. Y. \& Ling, X. Y. Plasmonic colloidosomes as three-dimensional SERS platforms with enhanced surface area for multiphase sub-microliter toxin sensing. Angew. Chem. Int. Ed. 54, 9691-9695 (2015).

18. Yang, M. Q., Han, C. \& Xu, Y. J. Insight into the effect of highly dispersed $\mathrm{MoS}_{2}$ versus layer-structured $\mathrm{MoS}_{2}$ on the photocorrosion and photoactivity of $\mathrm{CdS}$ in graphene-CdS-MoS 2 composites. J. Phys. Chem. C 119, 27234-27246 (2015). 
19. Zheng, L. X., Han, S. C., Liu, H., Yu, P. P. \& Fang, X. S. Hierarchical MoS Nanosheet@TiO, Nanotube Array composites with enhanced photocatalytic and photocurrent performances. Small 12, 1527-1536 (2016).

20. Chen, $\mathrm{Z}$. et al. Core-shell $\mathrm{MoO}_{3}-\mathrm{MoS}_{2}$ nanowires for hydrogen evolution: functional design for electrocatalytic materials. Nano Lett. 11, 4168-4175 (2011).

21. Yin, D. et al. 2D porous aromatic framework as a novel solid-phase extraction adsorbent for the determination of trace BPA in milk. Microchim. Acta 81, 749-758 (2018).

22. La, M. M. A. et al. Consensus on the key characteristics of endocrine-disrupting chemicals as a basis for hazard identification. Nat. Rev. Endocrinol. 16, 45-57 (2020).

23. Xie, S. Y. et al. Intelligent mesoporous materials for selective adsorption and mechanical release of organic pollutants from water. Adv. Mater. 30, 1800683 (2018).

24. Jia, F., Wang, Q., Wu, J., Li, Y. \& Song, S. Two-dimensional molybdenum disulfide as a superb adsorbent for removing $\mathrm{Hg}^{2+}$ from water. ACS Sustain. Chem. Eng. 5, 7410-7419 (2017).

25. $\mathrm{Yu}$, J. et al. Smart $\mathrm{MoS}_{2} / \mathrm{Fe}_{3} \mathrm{O}_{4}$ nano-theranostic for magnetically targeted photothermal therapy guided by magnetic resonance/photoacoustic imaging. Theranostics 5, 931-945 (2015).

26. Liu, X. et al. Facile synthesis of boron-and nitride-doped $\mathrm{MoS}_{2}$ nanosheets as fluorescent probes for the ultrafast, sensitive, and label-free detection of $\mathrm{Hg}^{2+}$. Analyst 140, 4654-4661 (2015).

27. Valdivia, A., Tweet, D. \& Conley, J. Atomic layer deposition of two dimensional $\mathrm{MoS}_{2}$ on $150 \mathrm{~mm}$ substrates. J. Vac. Sci. Technol. A 34 021515 (2016).
28. Zhou, $\mathrm{H}$. et al. Controlled formation of mixed nanoscale domains of high capacity $\mathrm{Fe}_{2} \mathrm{O}_{3}-\mathrm{FeF}_{3}$ conversion compounds by direct fluorination. ACS Nano 9, 2530-2539 (2015)

29. Zhu, H. et al. When cubic cobalt sulfide meets layered molybdenum disulfide: a core-shell system toward synergetic electrocatalytic water splitting. Adv. Mater. 27, 4752-4759 (2015).

30. Jiang, J. C. et al. Large-scale synthesis of single-crystalline iron oxide magnetic nanorings. J. Am. Chem. Soc. 130, 16968-16977 (2008).

31. Wang, Z. Q. et al. A platinum oxide decorated amorphous cobalt oxide hydroxide nanosheet array towards alkaline hydrogen evolution. J. Mater. Chem. A 6, 3864-3868 (2018).

32. Yang, S. et al. Monitoring the charge transfer process in a Nd-doped semiconductor based on photoluminescence and SERS. Technol. Light Sci. Appl. 9. 117 (2020).

33. Zheng, Z. H. et al. Semiconductor SERS enhancement enabled by oxygen incorporation. Nat. Commun. 8, 1993 (2017).

34. Chao, Y. F. et al. Self-assembly of flexible free-standing 3D porous $\mathrm{MoS}_{2}$ reduced graphene oxide structure for high-performance lithium-ion batteries. Adv. Funct. Mater. 27, 1700234 (2017)

35. Islam, S. E., Hang, D. R., Chen, C. H. \& Sharma, K. H. Facile and cost-efficient synthesis of quasi 0D/2D ZnO/MoS 2 nanocomposites for highly enhanced visible-light-driven photocatalytic degradation of organic pollutants and antibiotic. Chem. Eur. J. 24, 9305-9315 (2018).

36. Ling, $X$. et al. Raman enhancement effect on two-dimensional layered materials: graphene, h-BN and $\mathrm{MoS}_{2}$. Nano Lett. 14, 3033-3040 (2014).

37. Quan, Y. N. et al. ZnO nanoparticles on $\mathrm{MoS}_{2}$ microflowers for ultrasensitive SERS detection of bisphenol A. Microchim. Acta 186, 593 (2019). 